$$
\text { ociales }
$$

\title{
La participación del usuario en el Trabajo Social. Una mirada desde el presente hacia el humanismo de Concepción Arenal
}

\author{
Antonio Eito Mateo \\ DEPARTAMENTO DE PSICOLOGÍA Y SOCIOLOGÍA \\ UNIVERSIDAD DE ZARAGOZA \\ antoni@unizar.es
}

Resumen: Concepción Arenal fue una mujer adelantada a su tiempo en muchos aspectos. En lo referente a la "cuestión social" su obra y su reflexión sobre la atención a los más desfavorecidos no solo supuso un antes y un después, si no que muchas de sus reflexiones tienen indudable conexión con el Trabajo Social y su praxis en nuestros días.

Este artículo es una reflexión sobre la participación del usuario en la toma de decisiones que los Trabajadores Sociales hacemos en nuestras intervenciones profesionales, desde nuestro saber experto, conectándolo con la visión expuesta por Concepción Arenal en varias de sus obras, especialmente en el manual El Visitador del Pobre. Desde su visión humanista, Concepción Arenal pedía ver a los pobres de la época como víctimas, no como culpables, y rechazaba la arrogancia propia de los acomodados de la época que se acercaban a ayudar. Hoy los Trabajadores Socia-

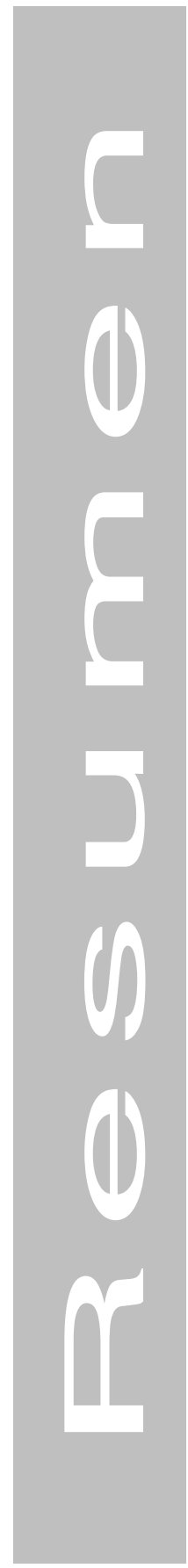

Acciones e Investigaciones Sociales, 32 (diciembre 2012), pp. 245-255 ISSN: 1132-192X 
les, profesionales formados, podemos caer en esa misma arrogancia si desde nuestro saber experto desdeñamos la participación de los usuarios, y nos consideramos como los poseedores de las únicas verdades y pautas válidas para intervenir.

Palabras clave: Concepción Arenal, Trabajo Social, relaciones poder, participación, saber profesional.

\title{
User involvement in Social Work. A look at the humanism of Concepción Arenal from a modern day perspective
}

\begin{abstract}
Concepción Arenal was a woman that in many respects was ahead of her time. With regard to the "social issue", her work and her reflection on providing care for the most disadvantaged not only represented a watershed, but also many of her reflections have an irrefutable connection with social work and its practice nowadays.

This article is a reflection on the participation of the user in taking the decisions that social workers take when we intervene in our professional capacity, from our expert knowledge, linking up with the vision exhibited by Concepción Arenal in several of her works, particularly in the handbook entitled The Visitor of the Poor. From her humanist standpoint, Concepción Arenal asked to see the poor of that time as victims, not as guilty people, and rejected the arrogance typical of her contemporaries that were comfortably off and came up to help. Nowadays, we social workers, who are trained professionals, can also fall into that same trap of arrogance if from our expert knowledge we frown on involving the users and consider ourselves to possess the only truth and valid guidelines for intervention.
\end{abstract}

Keywords: Concepción Arenal, social work, power relations, participation, professional knowledge. 


\section{La participación del usuario en el Trabajo Social. Una mirada desde el presente hacia el humanismo de Concepción Arenal}

Recibido: 27-04-2012

\section{LA PARTICIPACIÓN DEL USUARIO EN EL TRABAJO SOCIAL}

Desde sus inicios como disciplina científica el Trabajo Social se ha preocupado por la participación de los usuarios en los procesos de ayuda.

La propia Mary Richmond influenciada por el interaccionismo simbólico de Mead (Miranda 2010) manifestaba que los significados que las situaciones sociales tienen para los propios individuos son fundamentales para comprender mejor su situación.

Otra autora relevante como Gordon Hamilton señalaba acertadamente que "la ayuda es más efectiva si quien la recibe participa activamente y de una manera responsable en la ejecución del procedimiento" (citada por Zamanillo y Gaitán 1993:227).

Por tanto, podemos afirmar que hay un primer motivo o razón por el que la participación de los usuarios o clientes es fundamental en el Trabajo Social, la eficacia técnica. Es decir, con la participación de los usuarios se lograría un mayor éxito en las intervenciones de las y los profesionales. Contar no ya solo con su "acuerdo", si no hacerles partícipes en el diseño de la propia intervención y en la toma de decisiones es una baza que puede ayudarnos como profesionales en el trabajo cotidiano. 
Pero además, hay otra segunda gran razón, y esta es de corte deontológico. Tiene que ver con los valores del Trabajo Social, valores que se fundamentan tanto en reconocer la importancia de la participación, como en la capacidad de autodeterminación de los usuarios/clientes. Lo vemos en el Código de Ética de la Federación Internacional de Trabajadores Sociales (2004) en al apartado 4 que habla de los Principios:

"El trabajo social se basa en el respeto al valor y dignidad inherentes a toda persona, y a los derechos que de ello se desprenden. Los trabajadores sociales deben apoyar y defender la integridad y bienestar físico, psicológico, emocional y espiritual de cada persona. Esto significa:

1. Respetar el derecho a la autodeterminación. Los trabajadores sociales deben respetar y promover el derecho de las personas a elegir por sí mismos y a tomar sus propias decisiones, sea cuales sean sus valores y opciones de vida, siempre que no amenacen los derechos e intereses legítimos de otros.

2. Promover el derecho a la participación. Los trabajadores sociales deben promover el compromiso pleno y la implicación de los usuarios para reforzarles en la toma de decisiones y acciones que afectan a sus vidas" (FITS 2004).

Incluso en el Trabajo Social Comunitario la participación es también no ya un elemento fundamental, sino fundante, ya que como bien dice Marchioni (1999) sin participación no se puede hablar de Trabajo Social Comunitario, se podría hacer de Trabajo Social con orientación comunitaria o colectiva, con la comunidad como destinataria de una intervención, pero no de Trabajo social en, con y para la comunidad, de Trabajo Social Comunitario en definitiva.

Pero podríamos interrogarnos, ¿se produce verdaderamente esta participación del usuario en la toma de decisiones sobre situaciones qué afectan directamente a su vida, a su día a día vital, o no deja de ser una retórica ético-filosófico-científica?

\section{EL SABER EXPERTO}

Cualquier Trabajadora o Trabajador Social conoce conceptos y expresiones como empatía, acompañamiento o alianza terapeútica. 
La empatía es "una respuesta afectivo-cognitiva activada por el estado de otra persona y congruente con él, que orienta la conducta" (Ortiz, 1996:356). Dicho de otra manera algo así como la capacidad para ponerse en el lugar del otro. Ya decía Rogers que las tres características básicas de todo buen terapeuta para establecer una alianza terapéutica debían ser la empatía, la congruencia y la aceptación incondicional del otro. Alianza terapéutica que es un concepto ya clásico en psicoterapia, desde Freud, que veía como positiva una buena relación y transferencia entre el terapeuta y el ayudado. Pese a las diferencias entre escuelas y teóricos, lo que parece claro es que la dimensión relacional entre quien ayuda y quien recibe la ayuda es fundamental (Corbella y Botella 2003).

La relación de ayuda en el Trabajo Social, es un tipo de relación basada en la cercanía, en la confianza, en el "roce social". El trabajo se basa en promover el desarrollo positivo, el "acompañamiento social" (Aguilar y Llobet 2010). Otras autoras ven este acompañamiento como el "meollo" de la relación de apoyo (Pérez Eransus 2004) más allá de las posibles ayudas o prestaciones de las que disponga el sistema y que sin duda son necesarias (Aliena y Pérez Cosín 2001).

Pero estos valores, o formas de hacer, pueden ponerse en cuestión cuando el profesional sacraliza o pone en primer lugar su "saber experto", sus conocimientos, minusvalorando las capacidades o saberes de las personas que demandan ayuda. Y si bien la competencia técnica no solo es deseable, sino que es fundamental para la práctica profesional como veíamos en el apartado anterior, ésta no puede tomarse como la única opción válida y arrinconar la participación de los usuarios, so riesgo de caer en el asistencialismo o en el paternalismo.

$Y$ es que no debemos olvidar que el Trabajo Social se ejerce en un contexto de poder (la propia estructura social y profesional dónde ejercemos) y autoridad (los profesionales como expertos, como técnicos).

La forma en cómo se ejerce y cómo se pone en práctica el saber profesional puede ayudar a poner en marcha y activar valores, voces y saberes de los usuarios 0 , por el contrario, desactivarlos y minusvalorarlos. Cuestión que nos llevaría a la pregunta recurrente de si el Trabajo Social verdaderamente contribuye a la liberación/ayuda de las personas que solicitan la 
intervención y al cambio social o por el contrario no es más que otra herramienta de control social.

Pero también hay voces que señalan que los usuarios tampoco son tan "débiles" o la parte "más débil", como señala con gran tino a nuestro juicio Karen Healy hablando de las relaciones de poder y dominación en el Trabajo Social: "tan peligroso es decir que nunca se es víctima como afirmar que siempre se es" (Healy 2001:179). Propone que es fundamental conocer el poder macro (estructuras, leyes, reglamentos...) pero también en lo micro (cultural, género, relacional...) como una forma de contextualizar la acción profesional y ver cómo se ejerce el "saber experto", que no es siempre la misma en todos los "contextos". Por poner algunos ejemplos que animen al lector a la reflexión: ¿da igual qué el trabajador social sea hombre? ¿Y si es una mujer? ¿Cómo reaccionan los usuarios y las usuarias? ¿El contexto es igual con una situación de pobreza "tradicional" $o$ ante la solicitud de las ayudas de un dependiente de una familia "incluida" o con posibles?

\section{3. ¿Y CONCEPCIÓN ARENAL?}

Puede que algunas personas se pregunten, llegados a este punto, ¿cuál es la conexión con Concepción Arenal y su obra de nuestras anteriores palabras?

Si leer a Concepción Arenal siempre es un placer, sería fundamental que la lectura de alguna de sus obras fuese "obligatoria" en las Facultades de Trabajo Social para los estudiantes y futuros profesionales. Nuestra reflexión parte sobre todo de $E /$ Visitador del Pobre (1863).

Antes de entrar de lleno en la cuestión de la participación de los usuarios en el Trabajo Social, nos gustaría tratar aunque fuese brevemente la idea de Concepción Arenal de la participación en sentido general. Y es que ella creía en la necesidad de una sociedad civil participativa y en que hubiese cauces para ejercer esta participación, a través de la información, ya que el ciudadano debía ser el protagonista de las relaciones sociales (Capilla 2001). Estas ideas son sin duda un ejemplo de su "humanismo radical": "Concepción Arenal intentó desarrollar una opinión pública, crítica, humanista, sensibilizada hacia lo razona- 
ble, lo justo y lo natural' (Lacalzada 2012:486). Delegar el poder, la democracia, era para ella establecer una necesaria dialéctica entre gobernantes y gobernados, y cada avance, cada "verdad" conquistada socialmente y plasmada en la ley era un avance social, y un paso de la humanidad hacia su emancipación.

Sobre esta emancipación, sobre todo de los más desfavorecidos se preocupó especialmente en El Visitador del Pobre. La perfectibilidad para ella era una ley natural (Lacalzada 2012). Y esta solo podía desarrollarse en base a la toma de "conciencia de persona", siendo esta un avance en los grados de autonomía y soberanía personal, pero siempre dentro de su visión liberalorganicista con armonía con uno mismo, el entorno y los demás seres humanos. Y esta autonomía sólo podía lograrse en la medida en que se desarrollaban integralmente las capacidades $\mathrm{y}$ facultades morales, intelectuales, la sensibilidad, etc.

Todas estas capacidades debían de desarrollarse personalmente en una sociedad más justa, mediante la colaboración entre el Estado (garante del contrato social) y la creación de nuevas entidades (asociaciones diría ella) que podrían ayudar a mejorar los problemas de la sociedad tal y como se desarrollaban en otros países europeos.

A una de estas sociedades fue a la que dirigió su obra El Visitador del Pobre, dirigida no solo a las Hermanas de la Caridad de la congregación de San Vicente de Paúl sino "a todas las personas que procuran el consuelo de los pobres" (Lacalzada 2012:109).

El manual, escrito con gran habilidad y enclavado en las coordenadas humanistas, religiosas e ideológicas de la autora, es una llamada de atención en toda regla a la concepción que se tenía de la pobreza, y sobre todo de los pobres, desde las clases acomodadas y pudientes que eran quienes ayudaban en la época en que se publicó.

Frente a la caridad o la limosna, como una herramienta de salvación o de autoconstrucción del pedestal en el que se situaba el acomodado que daba la ayuda, criticaba esta superioridad, este sentirse mejor, y llevaba a cuestionarse ¿Quiénes somos? La arrogancia del ayudador, en realidad no hacía sino perpetuar la situación de pobreza, de exclusión de los ayudados. Como ella misma dice "estamos elevados accidentalmente sobre el pobre" (Arenal 1863:18). 
Su publicación fue toda una llamada de atención a su propia "clase social": "rara vez deja de notarse en nuestras palabras y acciones cierto desden hacia los que socorremos" (Arenal 1863:17). Sutilmente y con gran habilidad el manual trataba de penetrar en las conciencias de quienes lo leían, trataba de mover las conciencias y responder a la pregunta ¿quiénes somos?, mostrando el cariz social de muchos de los males de los que se acusaba a los pobres, a los necesitados. Ya que para Concepción Arenal el germen de la pobreza se encontraba en una mala distribución de la riqueza, atribuible a causas internas al propio individuo, pero también en relaciones creadas en la propia sociedad, por lo que era un fenómeno abordable y tenía solución (Arenal 1861).

Pero daba un paso más allá de esta llamada de atención, o de publicar un panfleto, El Visitador del Pobre incide en la necesidad de preparación de las y los visitadores, en su formación, e incluso en una llamada a la introspección antes de cualquier visita: "Entremos en nosotros mismos antes de entrar en la casa del pobre y preguntémonos. ¿Qué somos? ¿Qué hemos hecho para merecer nuestra posición? ¿Que hemos hecho para evitar las desgracias o los extravíos que deploramos en otros?" (Arenal 1863:18). Curiosamente, o quizá no tanto, una preocupación similar a la que tenía Mary Richmond, pionera del Trabajo Social como hoy lo conocemos, en Estados Unidos, cuando hablaba de sistematizar el Social Work, separando la acción profesional de la voluntaria, prácticamente en la misma época que Concepción Arenal, en un contexto y coordenadas éticas, religiosas, sociales, etc., totalmente diferentes (Miranda 2010:162-167).

\section{LA PARTICIPACIÓN DEL USUARIO EN EL VISITADOR DEL POBRE}

Concepción Arenal criticaba la prepotencia del que ayudaba, buscaba su formación y la reflexión sobre sus acciones, y al mismo tiempo criticaba y zarandeaba la sociedad de su tiempo.

Desde la introspección y la reflexión a la que movía su manual, ¿qué papel reservaba, si es que había alguno a la participación de los necesitados? ¿Debían ser meros destinatarios de la ayuda? A estas preguntas el lector ya responderá o quizá 
deducirá que la respuesta es negativa. Si criticaba esa forma de dar y de ayudar (asistencialista), sin duda pensaría en una forma de participar del ayudado.

Y lo vemos más gráficamente con sus propias palabras: "hagamos cuanto sea posible para que en todos los escollos vea su culpa; para que en todos los males vea las consecuencias de sus extravíos. Pero eso lo ha de ver él, no hemos de enseñárselo nosotros" (Arenal 1863:119-120).

Hasta en los casos más "desesperados" debería respetar la voluntad de la persona involucrada. Por eso, en el manual más que exponer casos ideales, lo que buscaba Concepción Arenal era que cada persona se descubriese a sí misma, ya fuese rico o pobre. Como bien dice Lacalzada (2012:112) el libro pretendía "buscar un despertar humanitario en los ricos y un sentimiento de autoestima en los pobres".

Para Concepción Arenal todas las personas y por supuesto los "pobres" tenían que encontrar su propio espacio de derechos, dignidad y participación en la sociedad a través de los medios que tenían a su alcance. En lograr este propósito debían volcar sus energías las personas que les prestaban su ayuda, pero siempre desde el respeto, desde una ayuda no arrogante, ni que prejuzgase, y buscando un cambio a mejor para toda la sociedad.

El manual trata de mostrar a las visitadoras que si hay alguna herramienta que puede ayudar en la labor que desarrollan, éstas son la prudencia, la sensibilidad y el respeto.

\section{LECCIONES DE LA LECTURA DE CONCEPCIÓN ARENAL A MODO DE DESPEDIDA}

Creo, personalmente, que cualquier persona interesada en el Trabajo en lo Social, en la Intervención Social y por supuesto en el Trabajo Social, tanto desde una vertiente voluntaria, como profesional, disfrutarán con la lectura de El Visitador del Pobre. Escrito con gran agilidad y con una gran profundidad en sus matizaciones, apreciaciones y orientaciones, Concepción Arenal logra con gran realismo plasmar algunas sugerencias y aportaciones encaminadas a capacitar y mejorar la relación de ayuda, desde el respeto a la otra persona, desde la empatía y la cercanía. 
En lugar de juzgar al otro, considerado como inferior o como merecedor de esa "suerte" de vida que padecía, proponía preguntarnos ¿quiénes somos? y qué es lo que nos diferencia de esas personas. Todo un aldabonazo para las clases más acomodadas de la época.

Hoy, con un Sistema de Bienestar desarrollado, parece que cuestionado también en una coyuntura socioeconómica como la actual, y con unas, aunque sea mínimas, garantías de derechos legales y sociales, la prestación de ayuda en gran medida está profesionalizada. Bien en las diferentes administraciones, bien en organizaciones y entidades sociales. Hoy no sé si muchos de estos profesionales pertenecemos a las clases acomodadas, pero sí sé que es muy posible que estemos situados en un nuevo pedestal, en este caso sacralizado por el "saber experto", por nuestros conocimientos que son superiores a los de muchas de las personas que vienen a pedirnos "ayudas".

Terminamos casi como comenzamos, recordando que tanto la eficacia técnica, como sobre todo la deontología profesional deberían obligarnos a bajarnos de ese pedestal en que puede convertirse el "saber experto", que puede hacer que cerremos oídos, sentimientos y saberes a otras voces que consideramos inferiores o portadoras de un no-saber, o que este saber es inferior. Trabajar, intervenir de esta forma, lejos de ser una ayuda, o incluso una prestación técnica, puede generar resistencia en el ayudado, algo de lo que ya se dio cuenta la propia Concepción Arenal.

Si olvidamos estos elementos básicos de nuestra profesión como Trabajadores Sociales, si no recordamos qué significa empatía, si la escucha activa se quedó en los apuntes de la universidad, si el acompañamiento pensamos que puede ser sustituido por prestaciones o simples ayudas, o que una entrevista puede ser reemplazada por un baremo o una escala de valoración, tal vez sea el momento de releer a Concepción Arenal y preguntarse ¿quiénes somos?

\section{Referencias bibliográficas}

AGUILAR HENDRICKSON, M. y LLOBET ESTANY, M. (2010). Debates fundamentales en el marco de la Inclusión Social en España. Madrid: Fundación Luis Vives. 
ALIENA MIRALLES, R. y PÉREZ COSíN, J. V. (2006). Más allá del paradigma de los recursos: Los servicios sociales, el trabajo social y sus retos [Resumen]. Acciones e Investigaciones sociales, Extra 1, p. 461.

ARENAL, C. (1861). La beneficencia, la filantropía, la caridad. Madrid: Imprenta de Tejado.

ARENAL, C. (1863). El Visitador del pobre. Madrid: Imprenta de Tejado.

CAMPO ALANGE, M. (1993). Concepción Arenal. Barcelona: Círculo de Lectores.

CAPILLA PÉREZ, A. (2001). Concepción Arenal: Un enfoque desde el Trabajo Social. Portularia, 1, 155-168.

CORBELLA, S. y BOTELLA, L. (2003). La alianza terapéutica: Historia, investigación y evaluación. Anales de Psicología, 2, 205-221.

FITS, Federación Internacional de Trabajadores Sociales. (2004). Código de Ética de la FITS. Berna: Autor.

HEALY, K. (2001). Trabajo Social: Perspectivas contemporáneas. Madrid: Morata-Paideia.

LACALZADA DE MATEO, M. J. (2012). Concepción Arenal: Mentalidad y proyección social $\left(3^{\mathrm{a}}\right.$ ed.). Zaragoza: Prensas Universitarias de Zaragoza.

MARCHIONI, M. (1999). Comunidad, participación y desarrollo: Teoría y metodología de la intervención comunitaria. Madrid: Editorial Popular.

MIRANDA ARANDA, M. (2010). De la caridad a la ciencia I: Trabajo Social: La construcción de una disciplina científica. Buenos Aires: Espacio Editorial.

ORTIZ, M. J. 1996. "El altruismo". En Morales, J. F. y Olza, M. (eds.) Psicología Social y Trabajo Social (pp. 349-369.). Madrid: McGraw- Hill.

PÉREZ ERANSUS, B. (2004). El acompañamiento social como herramienta de lucha contra la exclusión. Documentación Social, 135, 89-107.

ZAMANILLO, T. y GAITÁN, L. (1993). La investigación acción participativa en el trabajo social. Documentación social, 92, 225-240. 